\title{
Behavioral Economic Approaches to Increase Workplace Physical Activity from Research to Reality
}

\author{
Wendell C Taylor ${ }^{1 *}$ and Timothy F Page ${ }^{2}$ \\ ${ }^{1}$ Department of Behavioral Sciences and Health Promotion, Center for Health Promotion and Prevention Research, The University of Texas Health Science Center, \\ Houston School of Public Health, TX 77030, USA
}

${ }^{2}$ Robert Stempel College of Public Health and Social Work, Florida International University, FL, USA

"Corresponding author: Wendell C Taylor, Department of Behavioral Sciences and Health Promotion, Center for Health Promotion and Prevention Research, The University of Texas Health Science Center, Houston School of Public Health, 7000 Fannin Street, Suite 2670, Houston, Texas 77030, USA, Tel: 7135009635; Fax: 7135009602; E-mail: Wendell.C.Taylor@uth.tmc.edu

Received date: July 11, 2017; Accepted date: July 20, 2017; Published date: July 27, 2017

Copyright: $\odot 2017$ Taylor WC, et al. This is an open-access article distributed under the terms of the Creative Commons Attribution License, which permits unrestricted use, distribution, and reproduction in any medium, provided the original author and source are credited.

\section{Opinion Article}

The consequences of physical inactivity have been well documented [1]. Based on accelerometer data, only five to ten percent of Americans meet recommended guidelines for physical activity [2]. Barriers to physical activity include lack of time, concerns about neighborhood safety, lack of social support, and the monetary cost of equipment, workout attire, and gym fees $[3,4]$. Because of these barriers, the workplace has been identified as an optimal setting in which to increase physical activity. An innovative workplace intervention, the Booster Break program, is a group-based physical activity session designed for the 15-min work break led by a trained co-worker [5-11]. The theoretical foundations of the Booster Break program are Social Cognitive Theory, social support, intrinsic motivation, and selfrewards. The program reduces the impact of the aforementioned barriers to physical activity by embedding physical activity as part of the employee workday, which removes the barriers of time, cost, and unsafe environments. Attending one Booster Break session each workday would accumulate $75 \mathrm{~min}$ of physical activity each week; attending two Booster Break sessions each workday would accumulate 150 min of physical activity, meeting the Centers for Disease Control and Prevention's physical activity recommendations [4].

Quantitative and qualitative evidence supports the efficacy of the Booster Break program. Participants in a six month Booster Break program significantly improved their HDL levels and lost an average of 14 pounds [5]. Furthermore, other studies found that the Booster Break program encourages a mind set to adopt healthy behaviors, increases co-worker camaraderie, and promotes a health-enhancing culture at the workplace [6]. In a cluster-randomized controlled trial with three conditions $(n=175)$, Booster Break participants were 6.8 and 4.3 times more likely to have decreases in BMI and weekend sedentary time, respectively, than usual-break participants [8]. To illustrate the impact of the Booster Break program, a Booster Break participant stated that, "As a result of the nudge given by the Booster Break, now I have dropped 70 pounds and feel as though I am becoming a new person with a new viewpoint. I say without hesitation that as the pounds have dropped, my energy has increased and I credit the Booster Break with igniting afire in me" [7].

As with any workplace health promotion program or innovation, the challenge is the progression from efficacy to effectiveness. While the Booster Break program has demonstrated successful health improvements among those who attend regularly, as with many voluntary, workplace health promotion programs, maintaining high attendance levels is a challenge. To maintain and sustain high attendance rates during the Booster Break program, behavioral economic strategies provide a promising approach. Behavioral economic strategies (e.g., conditional payments, deposit contracts, regret lotteries, and point systems) have proven effective in promoting health behavior change for individuals outside of the workplace [12]. What is not known is whether behavioral economic strategies can increase physical activity in the workplace.

An article that recently appeared in Annals of Internal Medicine, published by Patel and colleagues, found that financial incentives were effective in promoting physical activity among overweight and obese adults [13]. The study tested three types of incentives: A gain incentive, where participants were paid $\$ 1.40$ for each day they met a daily goal of 7,000 steps; a loss incentive, where participants were allocated $\$ 42$ at the beginning of the month and then had $\$ 1.40$ deducted for each day they did not meet the goal; and a lottery incentive, where meeting the goal on one day permitted entry into a lottery the next day. They found that the loss incentive was the most effective in achieving the daily goal of 7,000 steps.

We are proposing to build on the findings of Patel and colleagues in two important ways. First, we plan to implement the financial incentives in workplaces participating in the Booster Break program to determine whether the findings translate to workplace health promotion programs. Second, to test whether competition is as effective in motivating employees as money, we plan to add a nonfinancial, point-based incentive, where employees with the highest scores at the end of the month receive company-wide recognition, for example on the company website or in a company newsletter. The competition-based incentive is significant in that it would be more sustainable than the financial incentives long-term because it would not require employers to devote funds to employee prize pools.

The Surgeon General of the United States stated that physical inactivity is the public health challenge of our times. A recent Call to Action from the Surgeon General is intended to create a culture of physical activity by promoting walking, wheelchair rolling, and walkable communities [14]. The Booster Break program contributes to this culture of physical activity by embedding opportunities for physical activity within the existing employee workday. While the program has thus far proven effective among those who attend it regularly, it is likely that financial and non-financial behavioral economic approaches may be necessary components to promote attendance among employees and therefore, improve the reach and impact of the program. Our approach can inform program development and implementation science because the progression of innovations from efficacy to effectiveness is a challenge for medicine, public health, and many other disciplines. 
Citation: Taylor WC, Page TF (2017) Behavioral Economic Approaches to Increase Workplace Physical Activity from Research to Reality. Health Econ Outcome Res 3: 134. doi:10.4172/2471-268X.1000134

Page 2 of 2

\section{References}

1. Proper KI, Singh AS, van Mechelen W, Chinipar MJ (2011) Sedentary behaviors and health outcomes among adults: a systematic review of prospective studies. Am J Prev Med 40: 174-182.

2. Tucker JM, Welk GJ, Beyler NK (2011) Physical activity in US: adults compliance with the physical activity guidelines for Americans. Am J Prev Med 40: 454-461.

3. http://www.cdc.gov/physical activity/worksite-pa/index.html

4. Physical Activity Guidelines Advisory Committee (2008) Physical activity guidelines advisory committee report. Department of Health and Human Services, Washington, DC, USA.

5. Taylor WC, Shegog R, Chen V, Rempel DM, Baun MP, et al. (2010) The Booster Break program: description and feasibility test of a worksite physical activity daily practice. Work 37: 433-443.

6. Taylor WC, King KE, Shegog R, Paxton RJ, Evans-Hudnall GL, et al. (2013) Booster Breaks in the workplace: Participants' perspectives on health-promoting work breaks. Health Educ Res 28: 414-425.

7. Taylor WC, Horan A, Pinion C, Liehr P (2014) Evaluation of Booster Breaks in the workplace. J Occup Environ Med 56: 529-534.
8. Taylor WC, Paxton RJ, Shegog R, Coan SP, Dubin A, et al. (2016) Impact of Booster Breaks and computer prompts on physical activity and sedentary behavior among desk-based workers: A cluster-randomized controlled trial. Prev Chronic Dis 13: 160231.

9. Taylor WC (2011) Prolonged sitting and the risk of cardiovascular disease and mortality. Curr Cardiovasc Risk Rep 53: 350-357.

10. Taylor WC (2011) Booster Breaks: An easy-to-implement workplace policy designed to improve employee health, increase productivity, and lower healthcare costs. J Workplace Behav Health 26: 70-84.

11. Taylor WC (2005) Transforming work breaks to promote health. Am J Prev Med 29: 461-465.

12. Huff N, Patel MS, Lim R, Zhu J, Troxel AB, et al. (2015) The role of behavioral economics incentive design and demographic characteristics in financial incentive-based approaches to changing health behaviors: A meta-analysis. Am J Health Promot 29: 314-323.

13. Patel MS, Asch DA, Rosin R, Small DS, Bellamy SL, et al. (2016) Framing financial incentives to increase physical activity among overweight and obese adults. Ann Intern Med 164: 385-394.

14. http://www.surgeongeneral.gov/stepitup 